\title{
System analysis of a polluted dynamic system of natural waters taking into account risks
}

\author{
Alexey Vertinsky, ${ }^{1, *}$ \\ ${ }^{1}$ Irkutsk National Research Technical University, 83, Lermontov str., 664074, Irkutsk, Russia
}

\begin{abstract}
The purpose of the study. A systematic study of the urgent problem of pollution of the natural water system and the evolution of water protection zones (boundaries), taking into account their dynamism and risks. A systematic approach is important not only because of the complex consideration of problems, but also to ensure the task of making systemic environmental decisions. Methods. The article uses the methods of systems analysis, statistical analysis, modeling, decision-making, optimization, classification (taxonomy) and risk management systems. Results. A system analysis has been carried out, on the basis of which procedures (algorithms) for modeling the system, algorithmic evaluation of the effectiveness of monitoring of water protection zones, dynamic water systems have been developed. The identification of the linear form from the nonlinear basic functions of the contribution of each pollution factor is used, taking into account the weight coefficients. An approach to the classification of water protection zones according to "tension" (taxonomic analysis) is also proposed. Conclusion. The performed system analysis takes into account the behavior of key (control) factors. This is necessary for the study of all subsystems - organizational and legal, socio-economic, environmental, technological, methodological support (education, consulting, training), etc. The results of the analysis and algorithms will make it possible to evaluate the parameters of water protection works, to solve various practical problems (for example, identification of the contribution to total pollution of each pollutant).
\end{abstract}

\section{Introduction}

The protection of water bodies, water protection zones of rivers, lakes, ponds in modern society and the developing "green economy" is particularly relevant. It plays a systemically significant role in the creation of an effective nature conservation activity in the studied areas.

The regions should identify the boundaries of the zones, create the appropriate GIS and maps, and the supervisory environmental service [1]. Information on water protection zones is included in the database of the State Water Register of the Federal Agency for Water Resources, information on the boundaries of zones is included in the USRN.

Legal responsibility arises in violation of the border regime and the use of the territory of water-protective and protective zones, management in them [2]. The water protection zone

*Corresponding author: vertin@bk.ru 
should prevent pollution, siltation, salinization and waterlogging, water depletion, and ensure the balance of biological resources in the habitat.

The implementation of the tasks of protecting water resources and providing them with them is limited by resource limitation and weak participation (at the expense of their net profit) of large and medium-sized businesses in socially significant environmental measures of the state. Water conservation programs are usually initiated at the regional-municipal level.

It is necessary to conduct an analysis with a systematic approach based on risk accounting, forecasting (modeling) processes in such a dynamic and complex system, followed by adaptive, sustainable management of water systems and activities. Taking into account the ecologically rational load of surface waters ("stress" of the medico-social and ecologicaleconomic system).

More than half a million compounds are used in industrial and economic activities, at least $10 \%$ of which are dangerous (especially when acting together) for humans, flora and fauna. When released into water bodies, these compounds worsen their condition; the use of such water requires expensive, complex and deep cleaning [3].

The legal regime of the protection zone of a water body prohibits or restricts:

1) placement of cemeteries, cattle burial grounds, gas stations, storage facilities for fuel, waste and hazardous, toxic substances;

2) gas stations and traffic flows (except for special vehicles and special equipped places on the roads);

3) discharge of sewage and drainage waters;

4) exploration and production of traditional minerals (with the exception of some cases), etc.

Water bodies are classified into groups:

1) surface - rivers, reservoirs, reservoirs, water sources (canals, ponds);

2) underground - waters, glaciers;

3) inland - seas, etc.;

4) territorial.

Water bodies should be considered systematically, as a complex of biogeocenoses, influencing the development of the population and its health, biological resources [4]. The world market of technologies (equipment) for water treatment amounted to more than 2.7 trillion rubles in today's terms in 2015, and almost 3.9 trillion rubles by 2020. Annual growth amounted to $7.4 \%$, it is provided by significantly leading market players - AECOM, Aquatech, Dow Water \& Process Solutions, Black \& Veatch, Evoqua Water Technologies and others (research by Research \& Markets, see [5]).

There are many drawbacks in the problem of wastewater: methodological, algorithmic, structural, infological, etc. For example, the development and use of relevant reagents, sorbents, situational monitoring and laboratory studies (for example, electrochemical [6]), taking into account the effect of summation, etc. However, the main drawback is the lack of a systemic, evolutionary (self-regulatory) approach [7]. This also applies to the improvement of the institutional structures of water protection [8], and the release of the researcher from the "captivity" of false security, pseudo-security [9], often understood in a narrow-subject, and not in a systemic sense, as security relative to the emergence of the system.

The article proposes a systematic analysis of the problem of pollution of a dynamic system of natural waters and a system-wide approach to solving such problems, supporting a decision-maker (DM).

\section{Methodology}

When forming the infrastructure for water protection of hazardous areas (for example, gas and oil production), it is necessary to have not only clear, relevant specifications and targetoriented resources, but also system analytics that support applied models and algorithms. It 
is required to take into account both multifactorial and multicriteria of the decisions made. For example, in the buffer zone of the oil and gas production sphere, it is necessary to take into account [10] not only the boundaries of the buffer zone, but also the boundaries of the near-wellbore zone, reservoir dynamics, duration of operation (current, expected), applied methods (for example, the skin effect [11]). Especially innovative, for example, isotope mapping of pollution [12], etc.

Each factor, each process listed above has its own risks that influence decision making and reduce operational efficiency.

To study the systemic and risk analysis of a dynamically polluted natural water system, it is necessary to select (adapt, design) the infrastructure of organizational and technological (technical) support for decision makers. Solutions are needed that are consistent with the system analysis-synthesis and modeling steps below.

1. Pre-model (pre-design) analysis of the system (buffer zone, its boundaries, water resources, a cluster of pollutants, situations, specifications, goals).

2. Resource-oriented assessment and ranking of goals, identification of emergent properties (properties inherent only in the considered water system, distinguishing it from other systems).

3. Design of protection measures, modeling of pollution and risks, prediction of damage, adaptively coordinated with the priority of goals, identification of specifications and scenarios.

4. Evaluation of modeling results (as a rule, it is situational, based on pre-selected, for example, experts or heuristically, scenarios for the development of the key water situations under consideration).

5. Adoption (generation) of a target decision, after analyzing the simulation results (visualization of scenarios and results is relevant here).

6. Iterative improvement of the made decision (from the stage of specifications to the stage of decision making).

For example, cartometric determination of coordinates of its boundary (for example, coastline) using GIS, remote sensing (ERS) using data from departmental (regional) and federal funds, for example, cadastral funds, is used in the case of identifying the boundary of a water protection zone [2].

This methodology, a modeling procedure, will allow not only to predict the state of the geodynamic system, but also to investigate both infrastructural and technical and technological characteristics. For example, to identify the redistribution of "tensions", "pressure" on the environment, to visualize them (see, for example, [13]).

We will consider this problem more specifically below.

\section{Results and discussion}

The algorithmized modeling procedure is implemented in the following way.

1. Identification of the infrastructure needs of the water protection zone, taking into account, for example, treatment measures.

2. Identification (parameterization) of target functions (functionals) for the implementation and development of the corresponding infrastructure.

3. Development of model situations (testing situations), flexible and not burdened with complex monitoring and complex models, forecasting (modeling) the evolution of the system, the situation in water protection boundaries.

4. Carrying out situational, simulation calculations for various parameters of the considered water protection zone, optimization of protection parameters, minimization of risks of pollution and damage to economic activities of enterprises, human health, flora-fauna. 
5. Assessment, computer monitoring of the state of the zone (possibilities of neutralizing possible pollution, maintaining the standard of living and production, in particular, removing impurities, etc.).

6. Iterative improvement of the "green economy" measures, reduction of risks of decreasing the quality of life and increasing the profitability of business.

Algorithmic evaluation of the effectiveness of the monitoring of dynamic water protection zones and water systems can be carried out by a procedure similar to that given below.

1. Preliminary analysis and rejection of rough statistical and monitoring data. This stage can be performed using Big Data [14], especially the use of Data Mining and Elastic Data is useful.

2. Testing of statistical hypotheses for the processes (control parameters) of the considered water system and analysis of correlations (hypotheses of the zero type, autocorrelation, etc.). 3. Regression and factor analysis, parametrization of relationships of potentially important (control) factors in the nature protection zone.

4. Assessment of predicted risks and effects. For this, the system of basic functions considered above is considered in general and formally, introducing functions $f_{i}(x), i=$ $1,2, \ldots m$, which can be used for a relevant assessment of pollution. For this system, we compose and identify the linear form of nonlinear functions:

$$
z=\sum_{j=1}^{k} a_{j} \sum_{i=1}^{m} b_{i}\left(x_{j}\right) f_{i}\left(x_{j}\right),
$$

where $k$ is the number of points for monitoring the situation, $a_{j}$ is the contribution, the "importance" of taking into account each point $j, b_{i}\left(x_{j}\right)$ - is the importance (power of influence) of the factor $x_{j}$ in the linear connection of the basis functions. For example, the debit value of water reserves is usually calculated using methodological and reference manuals or using factor analysis. We propose their prediction based on a linear expansion in the chosen system of basis functions, for example,

$$
\begin{gathered}
f_{1}(x)=\frac{a x+b}{c x+d}, \\
f_{2}(x)=e^{a x+b}, \\
f_{3}(x)=\frac{1}{\left(a+b e^{-c x}\right)}, \\
f_{4}(x)=\ln \left(\frac{a x+b}{c x+d}\right),
\end{gathered}
$$

where $x$ is the selected control factor, in particular, it can be permeability, pressure, etc.

5. Taxonomic analysis [15] makes it possible to divide water protection zones into classes, for example, "tension" $S(x)$, which, if we operate with the vector $x=\left(x_{1}, x_{2}, \ldots, x_{n}\right)$ parameters of water protection measures can be estimated as:

$$
S(x)=\sum_{i=1}^{N} p_{i}^{x_{i}}
$$

where

$$
S\left(N_{j}\right)=\frac{N_{j}}{\left[N_{j}\right]} S\left(N_{j}\right),
$$


$S(x)$ is the voltage frequency, $N$ is the number of water protection zones, subsystems, $p_{i}^{x_{i}}$ is the frequency of tensions with a risk of damage to $x_{i}$ and more zones, objects, $N$ is the number of different scenarios of risks, threats, $S\left(N_{j}\right)$ is the frequency of the scenario $N_{j}$.

6. Conducting monitoring studies or obtaining such data. The features of the zone will help to grasp the popular wavelet analysis [16], based on functions determined in the vicinity of the current point (for example, the initial point of the pollutant) and tending to zero rapidly with distance from the point, i.e. these are "short-wave" processes with zero integral action. 7. Making a decision on the state of the system, monitoring results (for example, by the commission or Delphi method) after discussing the results of clauses 1-6.

In the practical tasks of analyzing the pollution of the aquatic environment, the depletion of water layers [17], we propose to use the "skin effect" method, in contrast to this work.

If we operate with the vector $x=\left(x_{1}, x_{2}, \ldots, x_{n}\right)$ of the parameters of water protection measures (for example, $x_{1}$ is the water debit, $x_{2}$ is the cost of a unit of water protection works), then we can identify the profitability of work $y=f(x)$. The work is profitable for $y>$ 0 . For $y<0$, it will be necessary to modify the plan of water protection measures, and the program, environmental protection policy, possibly for a complexly connected zone boundary.

\section{Conclusion}

The practical tasks of monitoring, assessing and forecasting water resources are often approached narrowly in detail, haphazardly, considering a sufficient measure of "costeffectiveness to reduce damage" and similar ones. This approach makes it impossible to predict the evolution of the system, its self-organization.

A systematic analysis of the pollution of a dynamic system of natural waters and protected areas makes it possible to take into account the behavior and emergence of not only the entire system, but also its key subsystems, such as organizational, legal, economic, environmental, technological-monitoring, structural-algorithmic, methodological support and training.

The performed analysis and the presented procedure (algorithm) make it possible to identify (estimate) the needs, volumes and payback periods of water protection works. The work is evolving, the models and the algorithm are both complicated (for theoretical research) and adaptable to various flexible technologies for solving practical problems.

\section{References}

1. Water Code of the Russian Federation (2006) http://www.consultant.ru/document/cons_doc_LAW_60683/

2. A.S. Cheshev, D.I. Monakhov, Economy and Ecology of Territorial Entities 3, 40-44 (2017) DOI: https://doi.org/10.23947/2413-1474-2017-3-40-44

3. V.V. Polyakov, P.V. Polyakov, T.E. Alexandrova, Economy and ecology of territorial entities 2(4), 84-95 (2018) https://doi.org/10.23947/2413-1474-2018-2-4-84-95

4. A.S. Cheshev, A.V. Dyachenko, L.G. Dolmatova, Organizational and economic aspects of the use of irrigated lands (Vuzovskaya kniga, Moscow, 2011)

5. The volume of the world market of technologies for water and wastewater treatment, https://watermagazine.ru/novosti/za-rubezhom/19013-ob-em-mirovogo-rynkatekhnologij-dlya-ochistki-vody-i-stochnykh-vod-sostavit-k-2020-godu-54- mlrddollarov.html

6. A.P. Vertinsky, Technosphere safety 1(3), 45-52 (2016) 
7. V.M. Kaziev, B.V. Kazieva, Bulletin of the Dagestan State Pedagogical University. Natural and exact sciences 14(3), 5-10 (2020) DOI: 10.31161 / 1995-0675-2020-14-35-10

8. A.N. Krutov, Water Industry of Russia 3, 19-38 (2020) DOI: 10.35567 / 1999-45082020-3-2

9. A.A. Kuklin, N.V. Krivenko, L.A. Kryventsova, International scientific research journal 11(89).1 (2019) DOI: https://doj.org/10.23670/IRJ.2019.89.11.031

10. V.A. Silich, V.P. Komagorov, A.O. Saveliev, A.A. Alekseev, Reports of TUSUR 2(24).2, 295-299 (2001)

11. R.Sh. Mufalazov, ROGTEC Moscow 19, 8-36 (2007)

12. J. Podgorski, M. Berg, R. Kipfer IAEA Bulletin April, 31-32 (2019) https://www.iaea.org/sites/default/files/bull601april2019corr.pdf

13. P. Ogbeiwi, Y. Aladeitan, D. Udebhulu, J. Petrol Explor. Prod. Technol. 8, 271-289 (2018) https://doi.org/10.1007/s13202-017-0368-5

14. Big Data in Computational Social Science and Humanities, 1-25 (2018) DOI: 10.1007 / 978-3-319-95465-3_1

15. C.C. Belle, B.C. Stoeckle, Ju. Geist, Aquatic Conservation 29(11), 1996-2009 (2019) Doi: 10.1002 / aqc.3208

16. A.N. Yakovlev, Introduction to wavelet transforms (NSTU, Novosibirsk, 2003)

17. A.V. Zatonsky, I.N. Geraskina, V.V. Sterkhova, Bulletin of the Perm National Research Polytechnical University, series "Electrical engineering, information technology, control systems" 26, 171-182 (2018) 